\title{
Genç Sağlıklı Erkekte Dev Mesane Taşı: Olgu Sunumu
}

\author{
Giant Bladder Calculus In A Young And Healty Man: A Case Report
}

\section{Ural Oğuz, Çağrı Şenocak, Cengiz Kara, Ömer Faruk Bozkurt, Ali Ünsal}

Ankara Keçiören Eğitim ve Araştırma Hastanesi Üroloji Anabilim Dalı

Başvuru tarihi: 05.02.2010 • Kabul tarihi: 01.07.2010

İletişim

Dr. Ural Oğuz

Ankara Keçiören Eğitim ve Araştırma Hastanesi Üroloji Anabilim Dalı

Tel $\quad:$ : $\quad$ :903123569000

Gsm :05057226307

E-Posta Adresi : uraloguz@yahoo.com

Mesane taşları tüm üriner sistem taşlarının \%5'ini oluşturmaktadır. Sıklıkla ileri yaşı erkeklerde görülürler ve prostat hiperplazisi, nörojenik mesane gibi infravezikal obstruksiyonlara sekonder oluşurlar. Enfeksiyonlar, yabancı cisim, kadınlarda anti inkontinans cerrahisi ve nadiren gebelik mesane taşları için predispozan faktör olabilmaktedir. Endemik mesane taşları ise, çocuklarda ve herhangi bir predispozan faktör olmaksızın sağlıklı gençlerde görülebilmektedir. Bu oldu sunumunda dev endemik mesane taşı olan ve sistolitotomi yaptığımız 23 yaşındaki bir erkek hastayı sunduk. Taşın ağırlığı $102 \mathrm{gr}$, boyutları ise $53 \times 52 \times 43 \mathrm{~mm}$ olarak ölçüldü. Taş analiz sonucu ise kalsiyum oksalat taşı olarak rapor edildi. Bu dev mesane taşı için hiçbir predispozan faktör yoktu. Bu olgu sunumuyla hiçbir predispozan faktör olmaksızın genç ve sağlıklı erkeklerde de mesane taşı oluşabileceği ve DÜS grafi ve/veya üriner sistem USG ile kolaylıkla tanı konulabileceğini vurgulayı amaçladık.

\section{Anahtar Sözcükler: Dev Mesane Taşı, Etiyoloji, Genç Erkek}

Bladder calculi account for $5 \%$ of all urinary system calculi. They are usually seen in older men and occur because of infravesical obstructions such as prostate hyperplasia, neurogenic voiding dysfunction. Infection, foreign bodies, anti incontinence surgery in woman and rarely pregnancy can also be predisposing factors for bladder calculus. But they can be rarely seen in children and young, healthy patiants without any predisposing factors and are called endemic bladder calculi. In this case report we present a 23 years old man who has endemic giant bladder calculus and on whom we performed cystolithotomy. The stone weighed $102 \mathrm{gr}$ and measured $53 \times 52 \times 43 \mathrm{~mm}$ in size. And it was composed of calcium and oxalate. There were no predisposing factors in this giant bladder calculus. The aim of this case report was to emphasize the fact that bladder calculi can develop in young healthy men without any predisposing factors and that it can be diagnosed readily with DUSG and/or urinary tract USG.

Key Words : Gaint Bladder Calculus, Etiology, Young Man

Mesane taşı tarihi milattan önceye uzanır ve bugün insidansı tüm üriner sistem taşlarının \%5'ini oluşturur.(1) Çoğunlukla prostatizm semptomlarının artmasıyla birlikte 50 yaş üzeri erkeklerde görülür. Sıklıkla infravezikal obstruksiyonlar (BPH, nörojenik mesane, v.s), kronik bakteriüri, yabanci cisimler, mesane divertikülü ile birlikte görülürler. Ayrıca kadınlarda anti inkontinans cerrahisi de kolaylaştırıcı faktör olabilmektedir. $(2,3)$

Mesane taşlarını sıklıkla obstruktif üriner sistem semptomları olan hastalarda rastalantısal olarak görmekteyiz. Bu hastalarda eşlik eden dizüri, mikroskobik ya da makroskobik hematüri olabilir. Genellikle mesane taşları spontan ola- rak atılabilmekle birlikte büyük taşlar üretrada tam obstruksiyona neden olarak idrar çıkımını engelleyip globa neden olabilirler.(2,3). Ayrica dev mesane taşları tek taraflı ya da iki taraflı üreterohidronefroza neden olabilmektedir. (4) Çok nadir olmakla birlikte gebeliğin predispozan olduğu mesane taşı olguları da bildirilmiştir.(5)

$\mathrm{Bu}$ olgu sunumunda herhangi bir predispozan faktörü olmaksızın dev mesane taşı olan genç, sağlıklı erkek hastayı, konuyla ilgili literatürleri irdeleyerek paylaşmayı amaçladık.

\section{Olgu Sunumu}

23 yaşında erkek hasta kliniğimize özellik- 
le efor sonrası oluşan makroskopik hematüri ve ara ara olan suprapubik bölgede ağrı şikayeti ile başvurdu. Tam idrar tetkiki normal olan hastanın direk üriner sistem grafisinde (DÜSG) mesane lokalizasyonunda yaklaşı $5,5 \mathrm{~cm}$ boyutunda taşla uyumlu opasite olduğu görüldü (Şekil 1). Üriner sistem ultrasonografisinde(USG) ise mesane içerisinde yaklaşı $5,5 \mathrm{~cm}$ boyutunda hareketle yer değiştiren, hiperekojen, gölge veren taş izlendi ve üst üriner sistem normal olarak değerlendirildi (Şekil 2). Özgeçmiş ve soygeçmişte özellik olmayan hastanın anamnez ve fizik muayenesinde de üriner sisteme dair özellik yoktu. Hastaya öncelikle sistoskopi yapıldı ve üretranın ve mesanenin doğal olduğu görüldü. Takiben sistolitotomi ameliyatı ile taş tek parça halinde alındı. Taşın buyutu 53×52×43 $\mathrm{mm}$, ağırlığı ise 102 gr ölçüldü. Preoperatif ve postoperatif 6 . ayda yap1lan üroflowmetrik çalısmada obstruktif paterne rastlanmadı. Kan gazları normaldi. Metabolik araştırma yapılan hastada, 24 saatlik idrar analizi, kan biyokimyası ( kalsiyum, fosfor, ürik asit dahil) ve parathormon değerleri normaldi. Taş analiz sonucu kalsiyum oksalat taşı olarak rapor edildi. Postoperatif 3. ay, 6. ay ve 1.y1l kontrollerinde aktif şikayeti olmayan hastanın tam idrar tetkiki, DÜS grafisi ve üriner sistem ultrasonografisi normaldi.

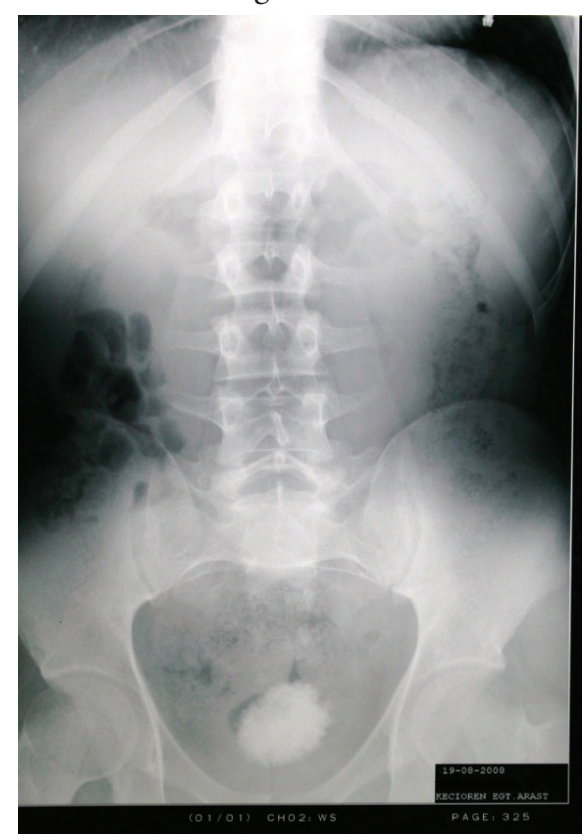

Şekil 1: Direk üriner sistem grafisi

\section{Tartışma}

Mesane taşları kedi ve köpeklerde çok yaygin olmakla birlikte insanlarda tüm üriner sistem taşlarının \%5 ini oluşturmaktadır. $(1,6)$ Genellikle eşlik eden predispozan faktörler bulunur. $\mathrm{BPH}$, nörojenik mesane, mesane divertikülü, kronik bakteriüri, üst üriner sistem taşları ve proteinden ve tuzdan zengin beslenme bunlardan bazılarıdır. $(1,2)$ Çok nadir olmakla birlikte gebelik de mesane taşı oluşumunda predispozan faktör olabilmektedir.(5) Obstruktif üriner sistem bulgularının sıklığı nedeniyle 50 yaş üzeri erkeklerde daha sık görülürler.(4) Çocuklarda ve gençlerde ise mesane taşı varlığında genellikle altta yatan bir konjenital üriner sistem anomalisi vardır.(6) Mesane ç1kım obstruksiyonları, üriner diversiyon, tekrarlayan üriner sistem enfeksiyonları mesane taşı nedenlerinden bazılarıdır. Özellikle Proteus Mirabilis gibi üreaz $(+)$ bakterilerin varlığında idrarda artan $\mathrm{pH}$ ve amonyum miktarı, taş oluşumunu kolaylaştırmaktadır.(7) Ayrıca bakteriyel enfeksiyonlarda glikozaminoglikan tabaka hasariyla kristallerin mukozaya yapışması da kolaylaşmaktadır.(8) $\mathrm{Bu}$ yazıda paylaştığımız olguda daha öncesinde üriner sistem enfeksiyon öyküsü yoktu ve postop takiplerinde bakteriüri olmadığı görüldü. Ayrıca mesane çıkım obstruksiyonu saptanmadı ve metabolik değerlendirmesi tamamen doğaldı.

Endemik mesane taşlarında genellikle ek ürolojik patoloji saptanmamaktadır. Ülkemizde de görülen endemik mesane taşları özellikle çocuklarda görülmektedir. Bu primer mesane taşlarının etyolojisi tam olarak bilinmemekle birlikte diyetle ilişkili olduğu düşünülmektedir.A vitamini eksikliğinde ve proteinden fakir beslenenlerde mesane taşı insidansının arttığı gösterilmiştir. $(1,6,9,10)$

Klinik olarak genellikle infravezikal obstruksiyonu olan hastalarda bu semptomların araştırılması sırasında tesadüfen fark edilir. Primer mesane taşlar1 ise sunduğumuz olguda olduğu gibi intermittan ya da sürekli hemetüri ve/ veya suprapubik ağrı ile kendini gösterebilir. En sık görülen semptom ise dizüridir. Ayrıca işemede güçlük hatta idrar retansiyonu gelişebilir.(11-12) Büyük mesane taşları nadiren tek taraflı ya da iki taraflı üreterohidronefroza neden olabilmektedir. $(4,12)$ Ayrıca bir olguda dev mesane taşının mesane perforasyonunu takiben ince barsak ve sigmoid kolon bası nekrozuna yol açarak akut batın tablosuna neden olduğu bildirilmiştir.(13)

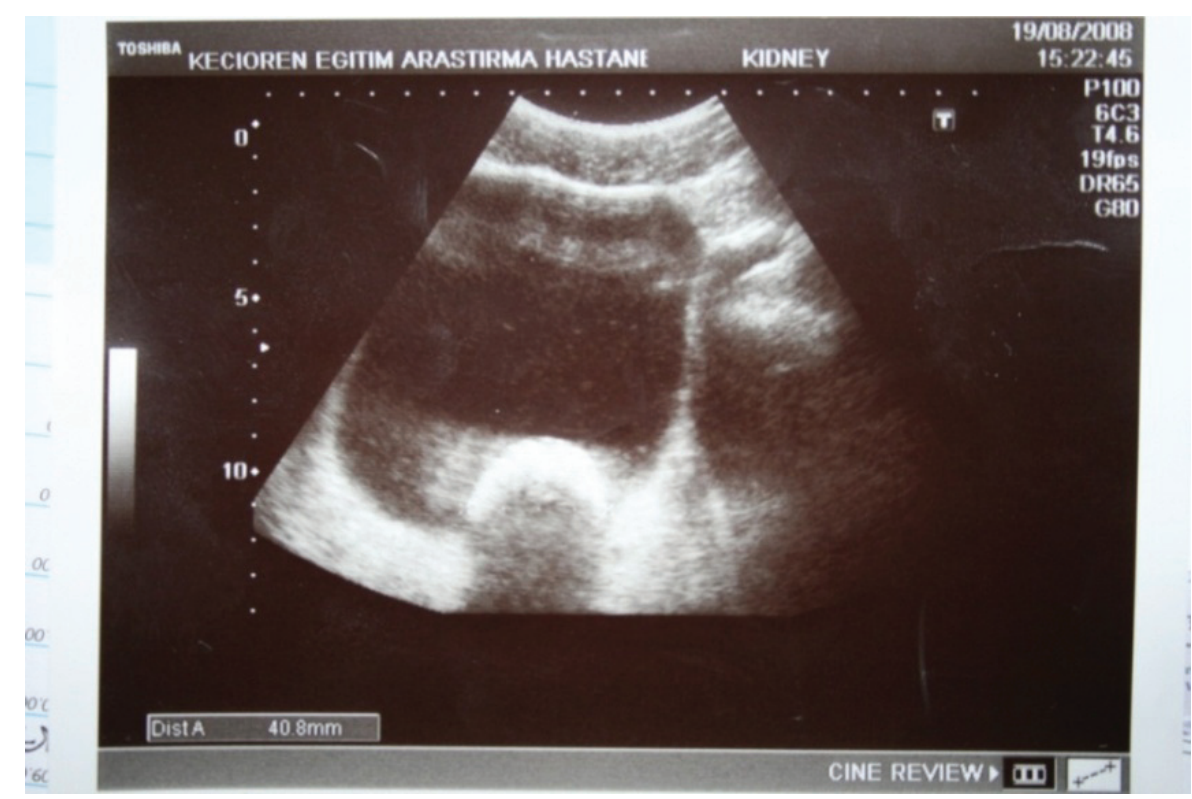

Şekil 2: Üriner sistem ultrasonografide mesane içerisinde hareketle yer değiştiren yaklaşık 5,5 $\mathrm{cm}$ boyutunda, hiperekojen, gölge veren taş 


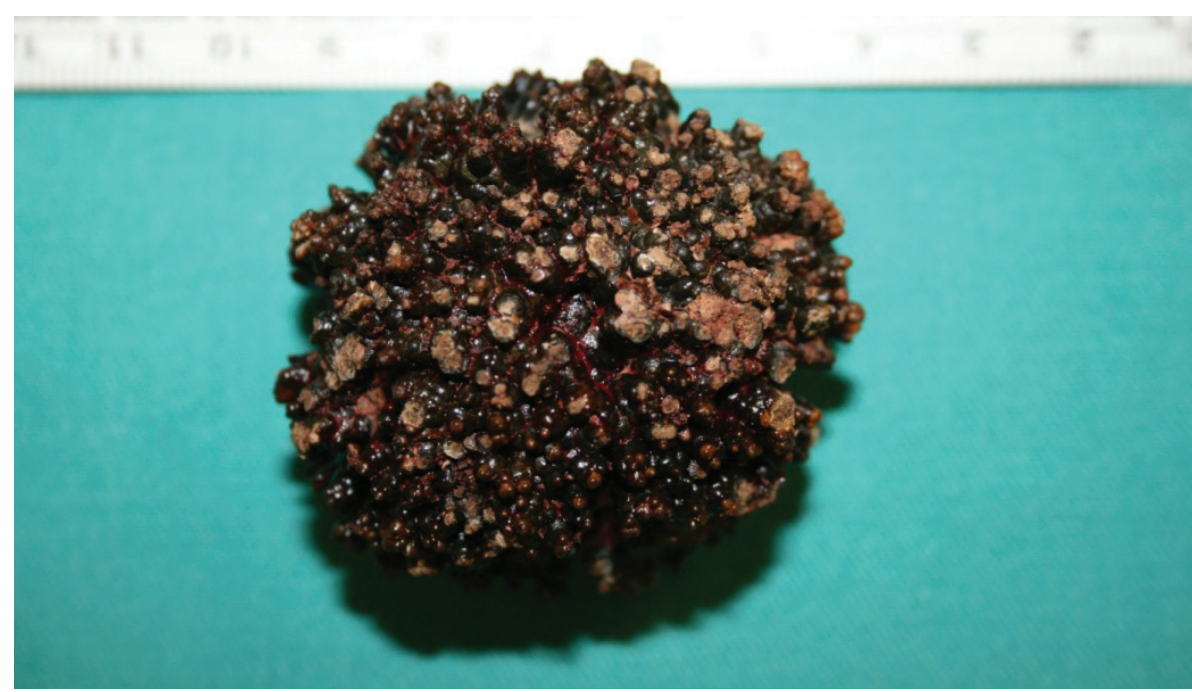

Şekil 3: çıkarılan taşın makroskobik görünümü. Mesane taşlarının tanısı DÜS grafi ile konulabilir, ancak ürik asit taşları ve bazı olgularda küçük taşların prostat dokusunun arkasında kalması nedeniyle DÜS grafide gözden kaçabilirler. (4) Non-opak taşların gösterilmesinde USG daha yararlıdır. USG de mesane içerisinde pozisyonla yer değiştiren ve gölge veren opasiteler görülür. En kesin tanı ise sistoskopidir. Böylelikle eşlik eden infravezikal bir obstruksiyon

\section{KAYNAKLAR}

1. Schwartz BF, Stoller ML: The vesical calculus. Urol Clin North Am 2000;27(2):33346.

2. Razvi HA, Song TY, Denstedt JD: Management of vesical calculi: Comparison of lithotripsy devices. J Endourol 1996; 10:559-63

3. Menon M, Bhalchondra GP, Drach GW: Urinary lithiasis: Etiology, diagnosis, and medical menagement . In Walsh PC, Retik AB, Vaughan ED Jr, Wein AJ(eds): Campbell's Urology, 7th ed. Philadelphia, WB Saundersr 1998, pp2661-773

4. Halil ÇİFTÇİ, Murat SAVAŞ: Dev mesane taşına bağlı tek taraflı hidronefroz. Türk üroloji dergisi. 2008, 34(2): 261-263

5. Escobar-del Barco L, Rodriquez-Colorado S, Duenas-Garcia OF, Avilez-Cevasco JC:Giant İntravesical calculus during pregnancy. Int Urogynecol J Pelvic Floor Dysfunct $2008,19(10): 1449-51$. varlığı da irdelenmiş olur.

Primer mesane taşlarının tedavisinde sistolitotomi, endoskopik sistolititripsi, perkutan sistolitotripsi, ESWL teknikleri tercih edilebilir. Çocuk ve genç hastalarda hem üretral çapın az olmas1, hem de üretra zedelenmesine neden olmamak için transüretral girişimler öncelikle tercih edilmemektedir.(14) Bu olgularda perkutan sistolitotripsi güvenli bir alternatif olabi-
6. Lebowitz RL, Vargaz B: Stones in the urinary bladder in children and young adults. AJR Am J Roentgenol. 1987, 148(3):491-5

7. Nemoy NJ, Staney TA: Surgical, bacteriological, and biochemical management of "infection Stones”. JAMA. 1971, 1;215(9):1470-6

8. Grenabo L, Hedelin H, Pettersson S: Adherence of urease- induced crystals to rat bladder epithelium. Urol Res. 1988;16(1):49-52

9. Turgut YAPANOĞLU, Yılmaz AKSOY, İsa ÖZBEY, Özkan POLAT: Çocuklarda perkutan suprapubik sistolitotripsi. Türk Üroloji Dergisi 2006, 32(2):199-202

10. Kancha RK, Anasuya A: Contribution of vitamin A deficiency to calculogenic risk factors of urine: Studies in children. Biocem Med Metab Biol. 1992, 47:1-9

11.Agrawal MS, Aron M, Goyal J, et al: Percuraneous suprapubic cystolithotripsy for vesical calculi in children. J Endourol. 1999, 13(3):173-5. lir. $(9,11)$ ESWL ise mesane taşlarında bir diğer tedavi seçeneğidir. ESWL'nin mesane taşlarındaki başarısı yüksektir ancak çocuklarda üretral çap dar olduğu için kırılan taşların düşmesi zor olabilir ve düşerken üretra hasarına neden olabilirler.(15) Taşsızlık oranı perkutan sistolitotripsi ile aynı olan sistolitotomi ise en eski ve tüm dünyada yaygın olarak kullanılan tedavi seçeneğidir. Büyük bir mesane taşı varlığında uzun süren bir elektrohidrolik litotripsiden ziyade açık bir prosedürü tercih etmek gerekmektedir; buna karşın BPH'e sekonder oluşmuş mesane taşlarında TUR-P işlemi sırasında küçük taşlar rezektoskopun içinden dişarı alınabilirler ya da kırıldıktan sonra yıkama ile dışarı alınabilirler.(16)

Sonuç olarak, özellikle ileri yaştaki, infravezikal obstruksiyon ve tekrarlayan üriner sistem enfeksiyonu olan hastalarda mesane taşı birlikteliği olabileceği gibi, genç hastalarda da hematüri ya da suprapubik ağrı semptomları sonrası mesane taşı olabileceği akılda tutulmalıdır; DÜS grafi ve/veya USG ile kolaylıkla tanı konulabileceği hatırlanmalıdır.
12. Komori K, Iwasaki A, Ikegami M, Kajikawa J, Kishimoto M: Giant bladder Stone Hinyokika Kiyo. 2000, 46:37-40

13. Boonstra RH, Blok AC, Van der Veen JH, Silvis R: Acute abdomen caused by a large vasical cystine calcules. Ned Tijdschr Geneeskd. 2006, 23;150:2800-2804

14. Mosbah A, Krid M, Baccouche S: Transurethral bladder lithotripsy using the Lithoclast in children. Apropos of 7 cases. Prog Urol.1995, 5:79-81

15. Goel MC, Baserge NS, Babu RV, et al: Pediatric kidney:Functional outcome after extracorporeal shock wave lithotripsy. J Urol. 1996, 155:2044-46

16. Guidelines on Benign Prostatic Hyperplasia; European Association of Urology Guidelines, 2009 